\title{
EARLY SYMPTOMS OF RHEUMATOID ARTHRITIS
}

\author{
BY \\ N. EGELIUS, N. G. HÄVERMARK, and ERIC JONSSON \\ Stockholm, Sweden
}

The opinion has been held in many quarters (e.g. Freund, 1929 ; Nyfeldt, 1944) that rheumatoid arthritis most often sets in insidiously and gradually. Kahlmeter (1944) considers it a characteristic feature of rheumatoid arthritis that it has "a predilection for small joints" and that the joint symptoms have a tendency to spread from peripheral joints and centripetally. Nevertheless, there are cases of rheumatoid arthritis that have an acute onset. According to this author, difficulty in differential diagnosis hardly exists.

Like Kahlmeter, many people distinguish between two forms of rheumatoid arthritis: one, as described by Charcot, with insidious onset, symmetrical joint symptoms, and low temperature ; and another with more acute onset, febrile reaction, and joint symptoms setting in violently. In British literature especially there are to be found these two types of rheumatoid arthritis under the respective designations of rheumatoid arthritis and infective arthritis. The terms " typical " or " primary " and " atypical" or " secondary" chronic are also not uncommon.

Comroe (1944) says that approximately 15 per cent. of the cases do not display the typical, insidious, and creeping start with symmetrical joint symptoms. In some 5 per cent. of cases the rheumatoid arthritis may be "atypical" for several months. These " atypical " cases may at times display symptoms in only one joint. Kinsella (1942) considers that when the disease sets in after the age of 50 it is acute at the outset and with a more rapid course and better prognosis. Ropes and Bauer (1945, cited by Hench and others, 1948) distinguish several types of (chronic) atypical rheumatoid arthritis : (1) with asymmetrical involvement, often a monarthritis ; (2) with sudden febrile onsets precipitated by acute infection and accompanied by skin rash and migratory joint involvement ; (3) bouts of arthritis precipitated by respiratory or other infections and not followed by permanent articular residues ; (4) with febrile onset resembling rheumatic fever (common among soldiers) ; (5) with transient swellings affecting one joint and then another, resembling " palindromic syndrome" ; (6) having recurrent joint and muscle aching and stiffness with qualitative characteristics of so-called " primary fibrositis ".

According to Ropes (1944a, b), typical advanced (chronic) rheumatoid arthritis presents little difficulty in diagnosis, but the so-called "atypical " forms are so common that it may be asked whether the " common" picture with insidious start, slowly progressing course, and symmetrical joint symptoms should be regarded as being the typical. Borman (1945), and Ropes and Bauer (1945) also point out the diagnostic difficulty in the "pre-arthritic" stage of rheumatoid arthritis.

\section{The Present Investigation}

We have long been interested in these questions and have gone through the records of two hundred patients with particular attention to early symptoms. All the cases were treated in Med. Dep. III of Södersjukhuset in recent years. Only cases of true rheumatoid arthritis have been considered.

We have distinguished the following types:

Type 1 is characterized by a slow and insidious onset and progressing course ; there is no fever, at least to begin with. The joints first involved are those of the peripheral extremities, and progress is centripetal and symmetrical.

Type 2 is characterized by an acute onset involving small joints. Sometimes there is fever, and in such cases the disease is clinically extremely reminiscent of rheumatic fever.

Type 3 is similar to type 2 except that the large joints are the first affected. The similarity to rheumatic fever is thus even more striking. It may be disputed whether one should and can make a distinction between types 2 and 3 , or whether these two groups should rather be merged in one.

Type 4 consists of cases where the joint symptoms are mainly confined to hands and feet for considerable periods. The joint symptoms are asymmetrical, and although they may be pronounced the skin symptoms and muscle atrophy are not. The 
sedimentation rate is low, and the tendency to progress relatively slight. This type of rheumatoid arthritis has been described by one of us (Jonsson) under the name of " atypical rheumatoid arthritis".

Type 5 starts with arthralgic symptoms : pain in joints without apparent objective joint changes. Arthralgia is often localized in the hands and may continue for long periods before objective symptoms appear.

Type 6 covers the remaining cases. In these the symptoms start in large or small joints, with or without fever. There is less symmetry, and in general the joint symptoms are difficult to characterize or classify. Extra-articular symptoms may occur.

We have distinguished a separate group of cases with the same division as the above, but with the difference that the course at the beginning was intermittent, so that there were periods without trouble alternating with periods when symptoms were present.

Our results are summarized in the Table. What impresses one most in looking at this table is that type 1, the so-to-speak " classical ", slowly progressing rheumatoid arthritis type with symmetrical joint symptoms, did not occur in more than 37.5 per cent., that is, in a little more than one third of the cases, whereas the types 2, 3, and 6 comprised 51.5 per cent. Even if the type 2 be subtracted, which of course is difficult to distinguish from type 1 as the joint symptoms in both groups start in small joints, we get the figure of $44 \cdot 5$ per cent., or nearly half.

The fact that type 4-the " atypical "- does not occur to the extent of more than 1 per cent. should not be any surprise. More striking, however, is that the cases starting with arthralgic symptoms are common enough to make 10 per cent. of the total. This illustrates the importance, even in cases of pain in the joint without demonstrable objective changes, of keeping the diagnosis of rheumatoid arthritis in mind. The Table also shows that the preponderance of women, noticeable in all groups, is particularly striking in this one.

Cases of type 6 represent no less than 30 per cent. As stated above, the joint symptoms here are in general difficult to characterize or classify. Even extra-articular symptoms occur, so that in these cases the clinical picture at the start of the disease may simulate, for example, peritendinitis calcarea, a stiff shoulder, a defect of the feet, etc. Symptoms may start in any joint.

From the Table it will be seen that the cases with intermittent symptoms are rather less common in type 1 than in the other types. As regards age of onset, the different types are the same.

Our material shows that early rheumatoid arthritis can be present in many forms and that the slow progressing type, which might be thought characteristic of rheumatoid arthritis, does not in fact occur as often as is sometimes supposed (compare Rope's statement above). We consider if justifiable to suspect early rheumatoid arthritis even when the symptoms are relatively uncharaco teristic.

\section{Summary}

Material from two hundred cases of rheumatoid arthritis has been collected. On the basis of the mode of onset, six types are distinguished. Type 1 starts insidiously, with symmetrical joint symptoms beginning

TABLE

ANALYSIS OF CASES OF RHEUMATOID ARTHRITIS ACCORDING TO TYPE

\begin{tabular}{|c|c|c|c|c|c|c|c|c|c|c|c|c|}
\hline & \multicolumn{2}{|c|}{$\begin{array}{l}\text { 1. Slow, pro- } \\
\text { gressing sym- } \\
\text { metrical } \\
\text { symptoms }\end{array}$} & \multicolumn{2}{|c|}{$\begin{array}{l}\text { 2. Acute start } \\
\text { in small joints }\end{array}$} & \multicolumn{2}{|c|}{$\begin{array}{l}\text { 3. Acute start } \\
\text { in large joints }\end{array}$} & \multicolumn{2}{|c|}{$\begin{array}{l}\text { 4. "Atypical" } \\
\text { benign cases, } \\
\text { hand foot and }\end{array}$} & \multicolumn{2}{|c|}{$\begin{array}{l}\text { 5. Arthralgia } \\
\text { symptoms }\end{array}$} & \multicolumn{2}{|c|}{$\begin{array}{l}\text { 6. Uncharac- } \\
\text { teristic } \\
\text { symptoms }\end{array}$} \\
\hline & M. & F. & M. & F. & M. & F. & M. & F. & M. & F. & M. & F. \\
\hline $\begin{array}{l}\text { Continuous } \\
\text { symptoms ... }\end{array}$ & 10 & 54 & 5 & 4 & 4 & 1 & - & 1 & 1 & 7 & 11 & 32 \\
\hline $\begin{array}{l}\text { Intermittent } \\
\text { symptoms }\end{array}$ & 4 & 7 & 1 & 4 & 3 & 9 & - & 1 & 1 & 11 & 5 & 24 \\
\hline \multirow{2}{*}{ Total cases } & 14 & 61 & 6 & 8 & 7 & 10 & - & 2 & 2 & 18 & 16 & .56 \\
\hline & \multicolumn{2}{|c|}{75} & \multicolumn{2}{|c|}{14} & \multicolumn{2}{|c|}{17} & \multicolumn{2}{|c|}{2} & \multicolumn{2}{|c|}{20} & \multicolumn{2}{|c|}{72} \\
\hline Percentage & \multicolumn{2}{|c|}{$37 \cdot 5$} & \multicolumn{2}{|c|}{7} & \multicolumn{2}{|c|}{$8 \cdot 5$} & & & \multicolumn{2}{|c|}{10} & \multicolumn{2}{|c|}{36} \\
\hline
\end{tabular}


in the peripheral joints and progressing centripetally. Type 2 starts as acute in the small joints, possibly with fever. Type 3 is like type 2 except that the joint symptoms begin in the large joints. The resemblance to rheumatic fever is striking. Type 4 consists of benign cases with asymmetrical joint symptoms and low sedimentation rate. Type 5 starts with arthralgic symptoms. Type 6 covers the remaining cases. The symptoms start in large or small joints with or without fever, and the symmetry is not particularly pronounced. Extraarticular symptoms may occur.

Type 1 occurs in only $37 \cdot 5$ per cent., types 2,3 , and 6 in not less than 51.5 per cent. of the cases. Type 6 occurs in 36 per cent. and type 5 in 10 per cent. The investigation shows that early rheumatoid arthritis may have a varied picture. One is justified in suspecting early rheumatoid arthritis even when the symptoms are relatively uncharacteristic.

\section{REFERENCES}

Borman, M. C. (1945). Wisc. Med. J., 64, 684.

Comroe, B. I. (1944). "Arthritis and Allied Conditions." London.

Freund, E. (1929). "Gelenkerkrankungen." Vienna. Hench, P. S., and others (1948). Ann. int. Med., 28, 66.

Jonsson, E. (1946). Nord. Med., 29, 189.

Kahlmeter, G. (1944). " Nordisk Laerebog i intern Medicin. II." Copenhagen.

Kinsella, R. A. Cit. from Hench and others (1948). Ann. int. Med., 28, 66.

Nyfeldt, A. (1944). "Forelaesninger over de rheumatiske Ledsygdomme." Copenhagen.
Ropes, M. W. (1944a). Bull. New Engl. Med. Center., $6,54$. (1944b). Arch. Phys. Therapy, 25, 397.

- , and Bauer, W. (1945). New Engl. J. Med., 233, 592,618 .

\section{Symptômes du Début de l'Arthrite Rhumatismale \\ RÉSUMÉ}

Des données concernant deux cent cas d'arthrite rhumatismale furent recueillies. En se basant sur le mode de début, on en distingue six types. Le type 1 commence d'une manière insidueuse, avec des symptômes articulaires symétriques débutant aux articulations périphériques et progressant vers le centre. Le type 2 commence d'une manière aiguë aux petites articulations, quelquefois avec de la fièvre. Le type 3 ressemble au type 2 sauf que les symptomes articulaires commencent aux grandes articulations. La ressemblance au rhumatisme articulaire aigu est frappante. Le type 4 comprend les cas benins avec des signes articulaires asymétriques et la sédimentation globulaire basse. Le type 5 débute par des symptômes arthralgiques. Le type 6 couvre les cas restants. Les symptômes apparaissent dans les articulations grandes ou petites, avec ou sans fièvre, et la symétrie n'est pas particulièrement prononcée. Des symptômes extra-articulaires peuvent se présenter.

Le type 1 se présente seulement dans 37.5 pour cent des cas, les types 2,3 et 6 dans pas moins de $51 \cdot 5$ pour cent. Le type 6 se présente dans 36 pour cent et le type 5 dans 10 pour cent des cas. L'investigation montre que l'arthrite rhumatismale du début peut présenter un tableau variable. On a le droit de soupçonner le début d'une arthrite rhumatismale même si, relativement, les symptômes ne sont pas caractéristiques. 